\title{
The renal effects of alginates isolated from brown seaweed Sargassum vulgare
}

\author{
Alessandra de Paula Alves Sousa, ${ }^{1}$ Paulo Sergio Ferreira Barbosa, ${ }^{1}$ Márcia Rocha Torres, ${ }^{1}$ \\ Alice Maria Costa Martins, ${ }^{2}$ René Duarte Martins, ${ }^{1}$ Renata de Sousa Alves, ${ }^{1}$ Daniel Freire de Sousa, ${ }^{2}$ \\ Claudênio Diógenes Alves, ${ }^{2}$ Letícia Veras Costa-Lotufo ${ }^{1}$ and Helena Serra Azul Monteiro ${ }^{1, *}$ \\ 1 Departamento de Fisiologia e Farmacologia, Faculdade de Medicina, Universidade Federal do Ceará, P.0. Box-3157, 60430-270, \\ Fortaleza, Ceará, Brasil \\ 2 Departamento de Análises Clínicas e Toxicológicas, Faculdade de Farmácia, Odontologia e Enfermagem, Universidade Federal \\ do Ceará, P.O. Box-3157, 60430-270, Fortaleza, Ceará, Brasil
}

Received 6 March 2007; Revised 25 May 2007; Accepted 1 June 2007

\begin{abstract}
Alginates isolated from Sargassum vulgare, present a strong antitumor activity, associated with kidney reversible damage, as analysed by histopathology of treated animals. In the present study, the renal alteration mechanisms of $S$. vulgare alginates were investigated using the isolated perfused rat kidney and the isolated perfused rat mesenteric blood vessel methods. The results showed that the effects of Sargassum vulgare low viscosity (SVLV) alginate were more potent than those of Sargassum vulgare high viscosity (SVHV) alginate in the isolated rat kidney. The SVLV alginate caused considerable changes in renal physiology, as shown by an increase in parameters such as perfusion pressure, renal vascular resistance, glomerular filtration rate, urinary flow and sodium, potassium and chloride excretion and by reduction of chloride tubular transport. The effects of SVHV were weaker than those of SVLV. The effects of SVLV on kidney could be related to direct vascular action as demonstrated with SVLV alginate on mesenteric blood vessels. In conclusion, the Sargassum vulgare alginate altered the renal function parameters evaluated. S. vulgare low viscosity alginate renal effects were more potent than $S$. vulgare high viscosity alginate. It is suggested that physicochemical differences between SVHV and SVLV could explain the differences found in the results. Copyright @ 2007 John Wiley \& Sons, Ltd.
\end{abstract}

KEY WORDS: alginates; Sargassum vulgare; nephrotoxicity

\section{Introduction}

Seaweeds have caused an emerging interest in the biomedical area due to their content of pharmacologically bioactive substances with great chances for use against bacteria, viruses, other pathogens and tumors (Blunden, 1993; Ireland et al., 1993; Smit, 2004). Of the substances that have received the most attention from pharmaceutical companies for the development of new drugs are the sulfated polysaccharides (antitumors and antivirals), the halogenated furanones (antifouling compounds) and the kahalalide F (anticancer and anti-AIDS compounds) (reviewed by Smit, 2004).

On the other hand, alginates have been extracted from seaweed for many years mainly for industrial purposes, being used as food additives in order to change and stabilize the texture of some foods. Alginates are polysaccharides composed mainly of linear polymers of $1 \rightarrow 4-\beta$-D mannuronic (M) and $\alpha$-L-guluronic acids differing in the

\footnotetext{
* Correspondence to: Helena Serra Azul Monteiro, Departamento de Fisiologia e Farmacologia, UFC, Nunes de Melo, 1127-CEP, 60430-270, P.O. Box 3157, Fortaleza, Ce, Brazil.

E-mail: serrazul@baydenet.com.br

Contract/grant sponsor: CAPES.

Contract/grant sponsor: CNPQ.

Contract/grant sponsor: FUNCAP.
}

proportions and in the linear arrangements. They possess the ability to form gel and to stabilize aqueous mixtures and emulsions (Moe et al., 1995). In the medical arena, the interest in alginates has shown a significant increase in the past decade. These molecules are already used in the microencapsulation of hormone-producing cells in the treatment of diabetes mellitus and parathyroid disease (Darquy and Sun, 1987; Fan et al., 1990) and they are also amongst the most popular carriers employed for the purpose of drug encapsulation (Pandey et al., 2005).

According to several authors, alginates present low toxicity, favorable mechanical properties and the capacity for bioresorption of the constituent materials, features that make them potential biopolymers suitable for the development of controlled-release systems (Lai et al., 2003). However, studies on alginate toxicity remain scanty. Most of them focus on the ability of these compounds to enhance host defenses and to prevent toxicity induced by other chemicals (Broderick et al., 2006; Mitsuhashi et al., 2006; Leung et al., 2006).

Recently, the anti-tumor activity has been demonstrated of two alginates with different viscosities extracted from the brown seaweed Sargassum vulgare C. Agardh against sarcoma 180 cells transplanted in mice. The histopathological analysis of the kidneys removed from treated 
animals showed acute tubular necrosis, suggesting an intrinsic nephrotoxicity associated with alginate treatment (Sousa et al., 2007). Thus, the aim of the present work was to investigate the nephrotoxicological mechanisms of $S$. vulgare alginates using the isolated perfused rat kidney and the isolated perfused rat mesenteric blood vessel methods.

\section{Material and Methods}

\section{Extraction and Purification of Alginates}

Specimens of the brown seaweed S. vulgare were collected in August 2004 on the Atlantic coast of Brazil (Pacheco Beach, Caucaia, Ceará), cleaned of epiphytes, washed in distilled water and stored at $-20{ }^{\circ} \mathrm{C}$. Alginates were extracted according to the method of Calumpong et al. (1999) with some modifications. The dried algae (300 g) were extracted at $60{ }^{\circ} \mathrm{C}$, fixed in $2 \%$ formaldehyde for $24 \mathrm{~h}$, and then washed in water. The thalli were put into $0.2 \mathrm{~N} \mathrm{HCl}$ for $24 \mathrm{~h}$ and washed again in water before extraction with $2 \%$ sodium carbonate. This mixture was homogenized, incubated in a water bath under continuous stirring at a temperature of $60{ }^{\circ} \mathrm{C}$ and then two samples were collected after $1 \mathrm{~h}$ and $5 \mathrm{~h}$ incubation. Crude extracts were collected after the centrifugation of these solutions whose precipitates were discarded, and then they were precipitated by the addition of ethanol in order to obtain the alginate fractions. These fractions were washed twice in acetone and dried. The intrinsic viscosities of the two samples obtained were comparatively analysed, and the alginates obtained after $1 \mathrm{~h}$ and $5 \mathrm{~h}$ incubation were named SVLV (S. vulgare low viscosity) and SVHV (S. vulgare high viscosity), respectively. The alginate fractions (SVLV and SVHV) were purified after dissolving them in distilled water, followed by an ethanol precipitation. The precipitates were then washed twice in acetone and dried.

The SVLV and SVHV alginates were physicochemically characterized by Torres (2003). The intrinsic viscosity of SVLV alginate was $5.26 \mathrm{dl} \mathrm{g}^{-1}$ while that of SVHV was $9.10 \mathrm{dl} \mathrm{g}^{-1}$. The alginates presented different molecular masses, being $19.3 \times 10^{4} \mathrm{~g} \mathrm{~mol}^{-1}$ for SVLV and $24.8 \times 10^{4} \mathrm{~g} \mathrm{~mol}^{-1}$ for SVHV. ${ }^{1} \mathrm{H}$ NMR spectra showed that the SVLV alginate possessed features of a high mannuronic acid (M blocks) content, while that of SVHV was shown to be of an intermediary kind (MG blocks). The SVLV alginate showed a higher proportion of $\mathrm{M} / \mathrm{G}$ (1.38) than the SVHV alginate (1.04).

\section{Isolated Perfused Rat Mesenteric Blood Vessels Method}

The mesenteric bed was perfused following the description of McGregor (1965). Wistar rats, weighing 280-
$350 \mathrm{~g}$, were anesthetized with sodium pentobarbitone (50 $\mathrm{mg} \mathrm{kg}^{-1}$ body weight). After opening the abdomen, the pancreatic-duodenal, ileum-colic and colic branches of the superior mesenteric artery were tied. The superior mesenteric artery was cleaned from surrounding tissues and cannulated by a polyethylene tube (PE20). The intestine was separated from the mesenteric bed by cutting close to the intestinal border. The mesenteric bed was perfused with Krebs-Henseleit solution containing: $114.0 \mathrm{~mm}$ $\mathrm{NaCl} ; 4.96 \mathrm{~mm} \mathrm{KCl} ; 1.24 \mathrm{~mm} \quad \mathrm{KH}_{2} \mathrm{PO}_{4} . \mathrm{H}_{2} \mathrm{O} ; 0.5 \mathrm{~mm}$ $\mathrm{MgSO}_{4} .7 \mathrm{H}_{2} \mathrm{O} ; 25.0 \mathrm{~mm} \mathrm{NaHCO}_{3} ; 2.10 \mathrm{~mm} \mathrm{CaCl} 2.2 \mathrm{H}_{2} \mathrm{O}$; and $3.60 \mathrm{~mm}$ glucose. The perfusion solution was kept warm at $37^{\circ} \mathrm{C}$ and the mesenteric bed was perfused at a constant perfusion pressure (PP) between 20 and $30 \mathrm{~min}$, while the variable perfusion pressure was measured by means of a P23 Statham pressure transducer (Gould, Oxnard, CA, USA) and recorded continuously on a DMP-4B Narco Bio-Systems Physiograph (Houston, TX, USA). The direct vascular effects of SVHV and SVLV $\left(10 \mu \mathrm{g} \mathrm{ml}^{-1} \mathrm{~min}^{-1} ; n=4\right)$ were examined and also evaluated for their effects on mesenteric beds previously precontracted with phenylephrine (1-5 $\mu \mathrm{m}$; to achieve 40-60\% maximal response).

\section{Kidney Perfusion}

Adult male Wistar rats (260-320 g) were fasted for $24 \mathrm{~h}$ with free access to water. The rats were anesthetized with sodium pentobarbitone $\left(50 \mathrm{mg} \mathrm{kg}^{-1}\right.$, i.p.). After careful dissection of the right kidney, the right renal artery was cannulated via the mesenteric artery without interrupting the blood flow as described by Bowman (1970) and modified by Fonteles et al. (1983). The perfusate consisted of a modified Krebs-Henseleit solution (MKHS) of the following composition (in $\mathrm{mmol} \mathrm{l}^{-1}$ ): $118.0 \mathrm{NaCl}$, $1.2 \mathrm{KCl}, 1.18 \mathrm{KH}_{2} \mathrm{PO}_{4}, 1.18 \mathrm{MgSO}_{4} .7 \mathrm{H}_{2} \mathrm{O}, 2.50 \mathrm{CaCl}_{2}$ and $25.0 \mathrm{NaHCO}_{3}$. Six grams of bovine serum albumin (BSA) was added to $100 \mathrm{~mL}$ of MKHS, and dialysed for $48 \mathrm{~h}$ at $4{ }^{\circ} \mathrm{C}$ against 10 volumes of MKHS. Immediately before the beginning of each perfusion protocol, $100 \mathrm{mg}$ urea, $50 \mathrm{mg}$ inulin and $50 \mathrm{mg}$ glucose were added to every $100 \mathrm{ml}$ of perfusate and the $\mathrm{pH}$ was adjusted to 7.4. In each experiment $100 \mathrm{ml}$ of MKHS was recirculated for $120 \mathrm{~min}$. An initial period of $20 \mathrm{~min}$ was allowed for blood washout. The perfusion pressure (PP) was measured at the tip of the stainless steel cannula in the renal artery. Samples of urine and perfusate were collected at 10 min intervals for analysis of sodium and potassium level by flame photometry; inulin, as described by Walser et al. (1955) and modified by Fonteles et al. (1983); and osmolality, which was measured in a vapor pressure osmometer (Wescor 5100C, USA).

The chloride analysis was carried out using a LabTest kit. SLHV $\left(10 \mu \mathrm{g} \mathrm{ml}^{-1}\right)$ and SVLV $\left(10 \mu \mathrm{g} \mathrm{ml}^{-1}\right)$ isolated from Sargassum vulgare was added to the system $30 \mathrm{~min}$ 


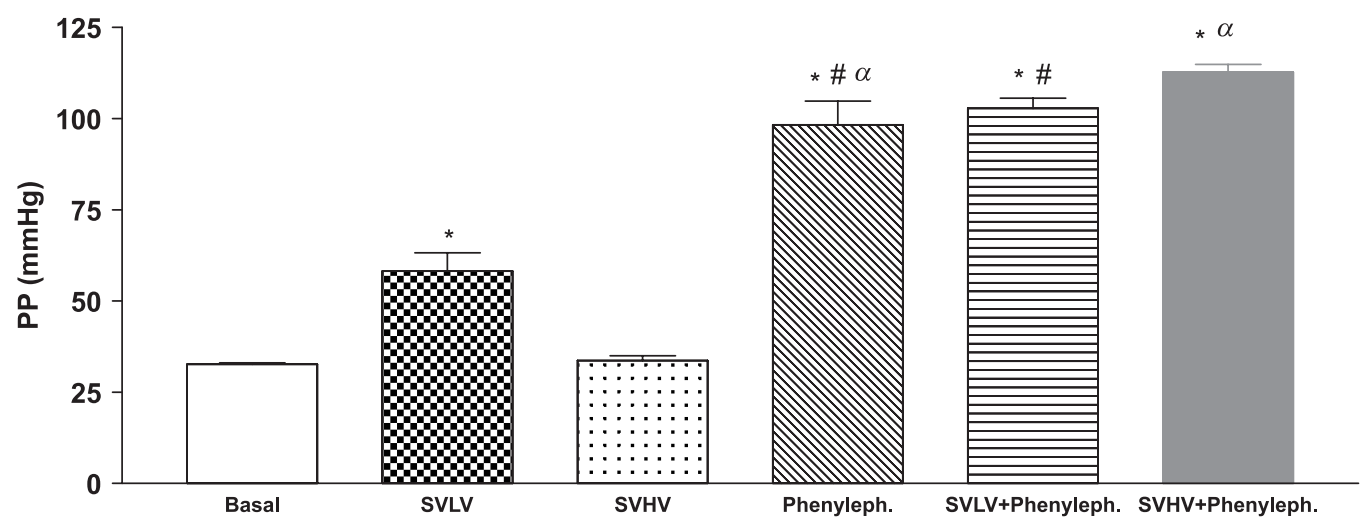

Figure 1. Effects of $S$. vulgare on the mesenteric blood vessel. Statistical analyses were done by ANOVA, compared with the basal pressure * $P<0.05$. " Compared with $S$. vulgare low viscosity (SVLV). ${ }^{\alpha}$ Compared with $S$. vulgare high viscosity (SVHV). Data are expressed as mean \pm SEM from six different animals. Statistical analysis was determined by analysis of variance (ANOVA) and corrected by Bonferroni test

after the beginning of each perfusion. The glomerular filtration rate (GFR), the percentage of sodium $\left(\% \mathrm{TNa}^{+}\right)$, potassium $\left(\% \mathrm{TK}^{+}\right)$and chloride $\left(\% \mathrm{TCl}^{-}\right)$tubular transport, the excretion of sodium $\left(\mathrm{ENa}^{+}\right)$, potassium $\left(\mathrm{EK}^{+}\right)$ and chloride $\left(\mathrm{ECl}^{-}\right)$, urinary flow (UF) and renal vascular resistance (RVR) were determined using conventional clearance formulas described in detail elsewhere (MartinezMaldonado and Opava-Stitzer, 1978).

\section{Statistical Analysis}

The results of both experiments are shown as the mean \pm SEM of four experiments for each group. Differences between groups were compared by using Student's $t$-test (non-parametric test) or analysis of variance (ANOVA) followed by Bonferroni test with significance set at $5 \%$.

\section{Results}

\section{Mesenteric Blood Vessel Effects}

The SVHV alginate neither affected the basal perfusion pressure nor interfered with the phenylephrine precontracted mesenteric vascular beds after 50 min of constant infusion. On the other hand, the SVLV alginate led to a basal pressure increase; however, it did not interfere with the phenylephrine precontracted mesenteric vascular bed after $50 \mathrm{~min}$ of constant infusion (Fig. 1).

\section{Renal Effects}

The SVHV alginate increased the perfusion pressure at $120 \mathrm{~min}$, and the renal vascular resistance at 90 and $120 \mathrm{~min}$ (Fig. 2). The glomerular filtration rate was also increased at $90 \mathrm{~min}$, but no alterations in urinary flow a)

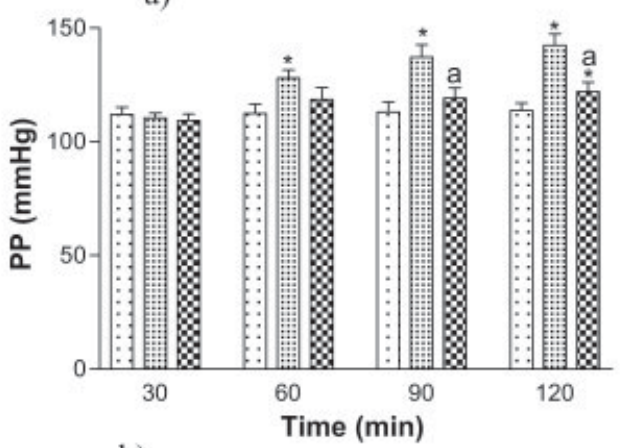

F.:- Control ment SVLV K\$ SVHV

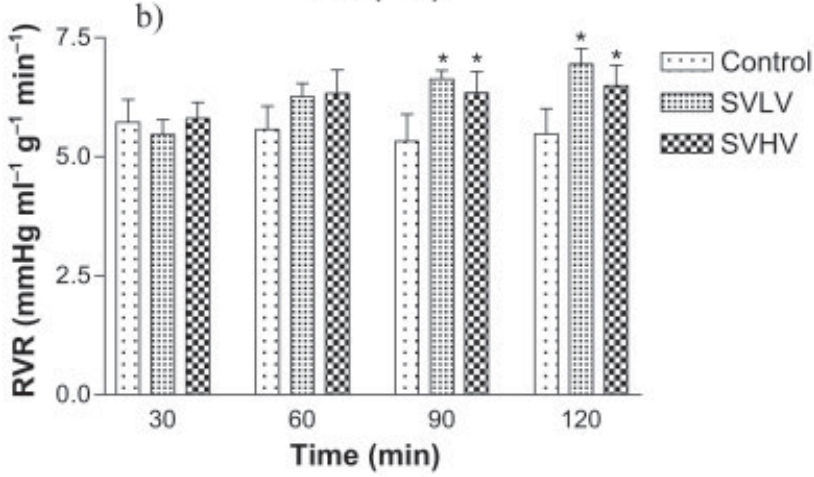

Figure 2. Effects of S. vulgare low viscosity (SVLV; $10 \mu \mathrm{g} \mathrm{m}^{-1}$ ) and S. vulgare high viscosity (SVHV; $10 \mu \mathrm{g} \mathrm{ml}^{-1}$ ) on perfusion pressure (PP; a) and renal vascular resistance (RVR; b). Statistical analyses were done by ANOVA, compared with a control group * $P<0.05$. a Comparison between SVLV group and SVHV group. Data are expressed as mean \pm SEM from six different animals. Statistical analysis was determined by analysis of variance (ANOVA) and corrected by Bonferroni test

were observed (Fig. 3). The percentage of chloride tubular transport was reduced after $90 \mathrm{~min}$, while sodium and potassium tubular transport showed no alterations (Fig. 4). Sodium and chloride excretion increased at 120 and $90 \mathrm{~min}$, respectively (Fig. 5). 

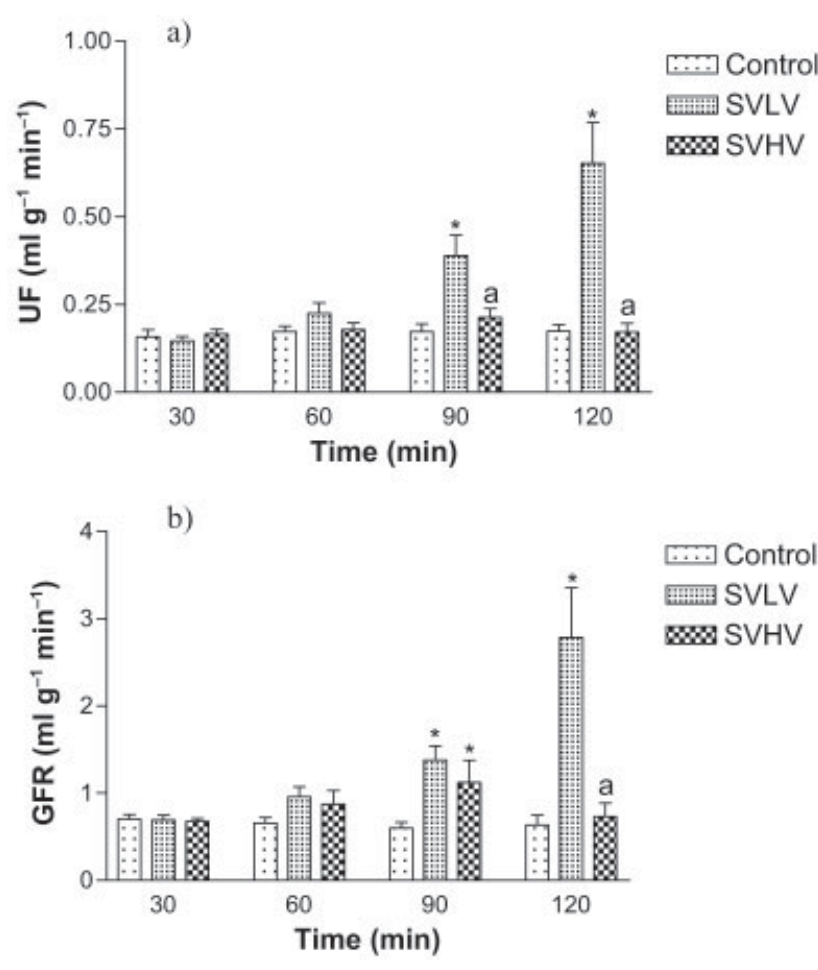

Figure 3. Effects of S. vulgare low viscosity (SVLV; $10 \mu \mathrm{g} \mathrm{ml}^{-1}$ ) and S. vulgare high viscosity (SVHV; $10 \mu \mathrm{g} \mathrm{ml}^{-1}$ ) on urinary flow (UF; a) and glomerular filtration rate (GFR; b). Statistical analyses were done by ANOVA, compared with a control group * $P<0.05$. ${ }^{\text {a Comparison }}$ between SVLV group and SVHV group. Data are expressed as mean \pm SEM from six different animals. Statistical analysis was determined by analysis of variance (ANOVA) and corrected by Bonferroni test

On the other hand, the SVLV alginate showed stronger effects in all analysed parameters. It increased the perfusion pressure at 60,90 and $120 \mathrm{~min}$, the renal vascular resistance, the glomerular filtration rate and the urinary flow at 90 and $120 \mathrm{~min}$ (Fig. 3). The percentage of chloride tubular transport was reduced at 60,90 and $120 \mathrm{~min}$, but sodium and potassium tubular transport showed no alterations (Fig. 4). Sodium, potassium and chloride excretion increased at 60, 90 and 120 min (Fig. 5).

\section{Discussion}

Alginates isolated from Sargassum species have been studied in the past few decades as new anticancer compounds using different animal tumors (Fujihara et al., 1984; Fujihara and Nagumo, 1992; 1993; Sousa et al., 2007). This activity seemed to be related to their immunostimulant properties, since these molecules have no direct cytotoxic activity; moreover they led to an enlargement of the white pulp of the spleen of treated animals (Sousa et al., 2007). In fact, there is a consensus
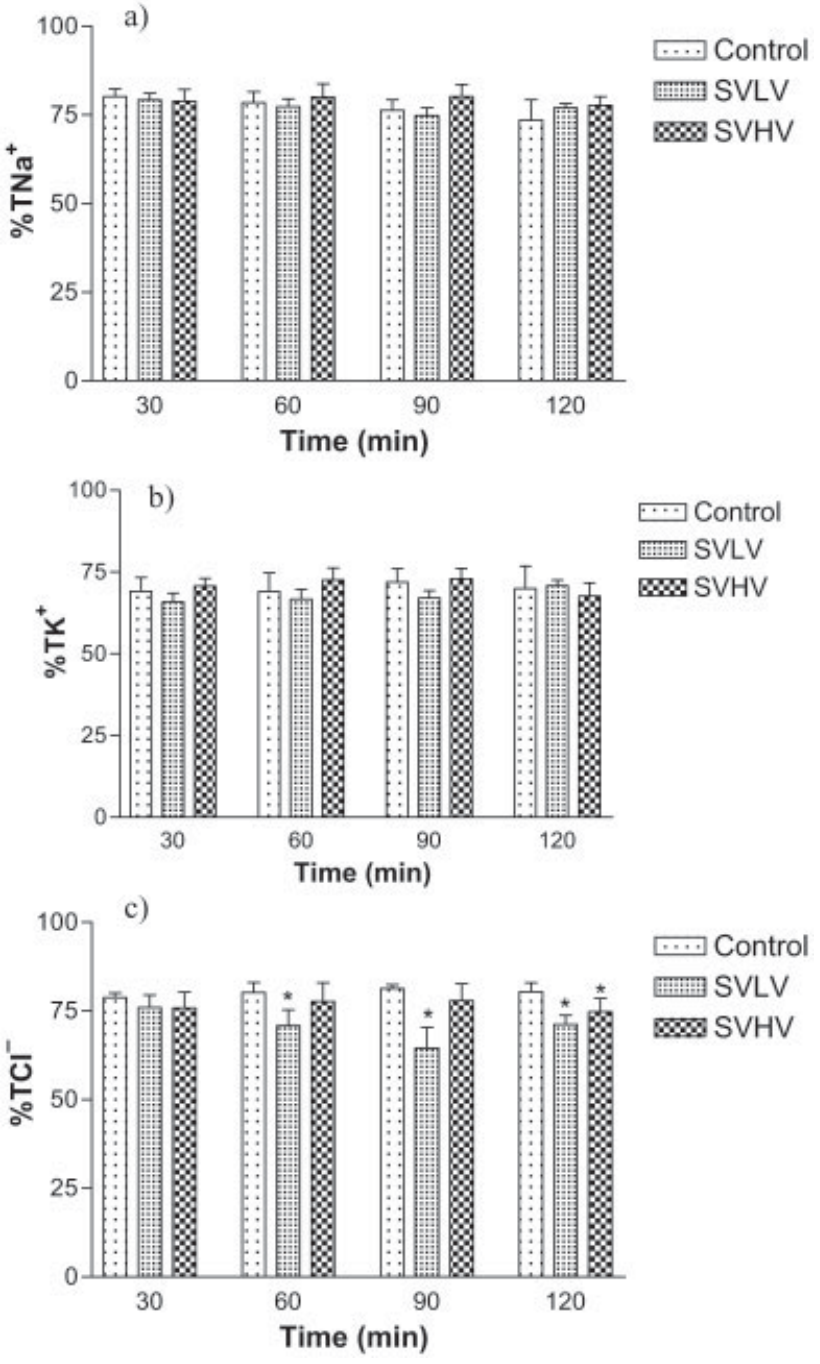

Figure 4. Effects of $S$. vulgare low viscosity (SVLV; $10 \mu \mathrm{g} \mathrm{ml}^{-1}$ ) and S. vulgare high viscosity (SVHV; $\left.10 \mu \mathrm{g} \mathrm{ml}^{-1}\right)$ on the percentage of sodium tubular transport $\left(\% \mathrm{TNa}^{+} ; \mathrm{a}\right)$, the percentage of potassium tubular transport $\left(\% \mathrm{TK}^{+} ; \mathrm{b}\right)$ and the percentage of chloride tubular transport (\% $\mathrm{TCl}^{-}$; c) Statistical analyses were done by ANOVA, compared with a control group * $P<$ 0.05 . Data are expressed as mean \pm SEM from six different animals. Statistical analysis was determined by analysis of variance (ANOVA) and corrected by Bonferroni test

that polysaccharides act as biological response modifiers, possessing promising immunomodulatory properties (Ooi and Liu, 2000; Leung et al., 2006).

Studies on the pharmacokinetics of alginates remain scanty, and there are no data about acute intoxication with S. vulgare. According to Hagen et al. (1996), sodium alginates were not absorbed following in vivo oral administration, while the bioavailability of alginates was approximately $44 \%$ following i.p. administration and lower than $5 \%$ following subcutaneous administration. 

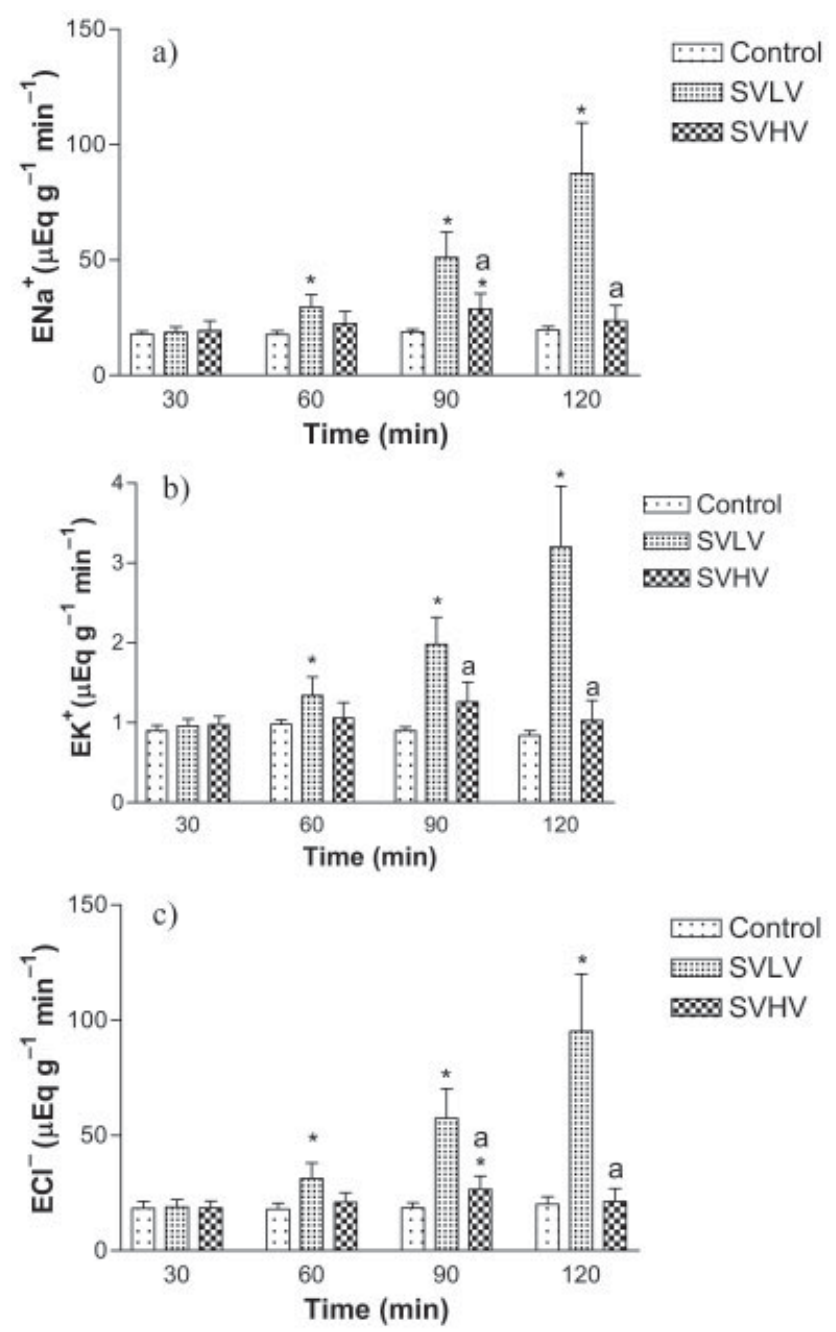

Figure 5. Effects of S. vulgare low viscosity (SVLV; $10 \mu \mathrm{g} \mathrm{ml}^{-1}$ ) and S. vulgare high viscosity (SVHV; $10 \mu \mathrm{g} \mathrm{ml}^{-1}$ ) on the excretion of sodium (ENa+; a), potassium $\left(\mathrm{EK}^{+} ; \mathrm{b}\right)$ and chloride $\left(\mathrm{ECl}^{-}\right.$; c) Statistical analyses were done by ANOVA, compared with a control group

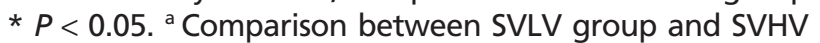
group. Data are expressed as mean \pm SEM from six different animals. Statistical analysis was determined by analysis of variance (ANOVA) and corrected by Bonferroni test

However, in a previous work the antitumor activity of oral or i.p. Sargassum vulgare alginates (SVLV and SVHV) was demonstrated, suggesting that these molecules are in fact absorbed despite the route of administration (Sousa et al., 2007). In the anticancer studies, the doses used were 50 and $100 \mathrm{mg} \mathrm{m}^{-2}$, giving about 200 and $400 \mu \mathrm{g} /$ animal. The idea in the present paper was to test the highest possible concentration. Thus, $100 \mu \mathrm{g} \mathrm{ml}^{-1}$ was used first (which is compatible to more than 50\% absorption, considering a total blood volume around $10 \%$ of the total body weight) but the effect was too strong, and it was impossible to analyse data for SVLV, so it was decided to reduce the concentration 10 times.
Concerning the toxicological aspects of alginate treatment, as mentioned before, it was observed that the kidney could be considered as a target organ in the toxicity of these compounds (Sousa et al., 2007). Thus, in the present study, the renal effects of alginates (SVLV and SVLV) isolated from $S$. vulgare were assessed using isolated rat kidneys, and it was also verified whether the effects observed on the kidney could be related to vascular alterations.

The results pointed out that SVLV alginate effects were more potent than those of SVHV alginate in isolated rat kidney. SVLV presents a typical change in renal function due to an increase in vascular pressure in glomerular capillaries, increasing PP, RVR, GFR, UF and sodium, potassium and chloride excretion and reducing chloride tubular transport. Otherwise, the effects of SVHV were different probably due a modification in tubular function and/or in the renal handling of water.

These data corroborate previous studies based on morphological and histopathological analyses of the kidneys from both SVLV and SVHV treated animals. Treated animals showed several degrees of hydropic changes and vacuolization of the cytoplasm of proximal tubular epithelium and glomerular and tubular hemorrhage, but only in the kidney removed from SVLVtreated animals, were the cells lining the tubules necrotic (Sousa et al., 2007). Thus, SVLV could be considered more toxic to the kidney also in vivo.

The present data also suggested that the effects of SVLV on kidney could be related to direct vascular effects as demonstrated by the SVLV alginate action in mesenteric blood vessel. This may be due to a similar mechanism in these tissues.

Many authors have discussed the influence of the content of D-mannuronic and L-guluronic acid in alginates in blocking biological antitumor activity (Fujiihara and Nagumo, 1992; 1993; Sousa et al., 2007). The SVLV alginate showed a higher proportion of $\mathrm{M} / \mathrm{G}$ (1.38) than the SVHV (1.04). The SVHV alginate showed fractions of $\mathrm{F}_{\mathrm{GGG}}=0.214 ; \mathrm{F}_{\mathrm{MM}+\mathrm{MG}}=0.667 ; \mathrm{F}_{\mathrm{GGM}+\mathrm{MGM}}=0.118$, while the SVLV alginate showed fractions with $\mathrm{F}_{\mathrm{MM}}=$ 0.6 and $\mathrm{F}_{\mathrm{GGG}}=0.4$, and GGM and MGM fractions were not observed (Torres, 2003). Panikkar and Brasch (1996) proposed a classification system with three kinds of alginates based on the monomer composition: alginates with 'high $\mathrm{M}$ blocks content' (where $\mathrm{F}_{\mathrm{M}}$ is greater than or equal to 0.7 ); alginates with 'high $\mathrm{G}$ blocks content' $\left(\mathrm{F}_{\mathrm{M}}\right.$ is less than or equal to 0.6$)$ and intermediate alginates possessing $\mathrm{MG}$ blocks $\left(\mathrm{F}_{\mathrm{M}}\right.$ between 0.6 and 0.7). Based only on this classification system, the SVHV is an alginate of intermediate type (0.67), while the SVLV (0.6) is similar to a high G block content one. However, the block structure particular to SVLV represented a high content of mannuronic acid in opposition to the classification of Panikkar and Brasch (1996). 
In conclusion, the $S$. vulgare alginate altered the renal function parameters evaluated. The $S$. vulgare low viscosity alginate renal effects were more potent than $S$. vulgare high viscosity alginate. It is suggested that physicochemical differences between SVHV and SVLV possibly could explain the differences found in the results.

Acknowledgements-The authors are grateful to the Brazilian Agencies CAPES, CNPQ and FUNCAP for fellowship and financial support.

\section{References}

Blunden G. 1993. Marine algae as sources of biologically active compounds. Interdiscip. Sci. Rev. 18: 73-80.

Bowman RH. 1970. Gluconeogenesis in the isolated perfused rat kidney. J. Biol. Chem. 245: 1604-1612.

Broderick E, Lyons H, Pembroke T, Byrne H, Murray B, Murray M. 2006. The characterization of a novel, covalent modified, amphiphilic alginate derivative, which retains gelling and non-toxic properties. J. Colloid Interface Sci. 298: 154-161.

Calumpong PH, Maypa PA, Magbanua M. 1999. Population and alginate yield and quality assessment of four Sargassum species in Negros Island, central Phillipines. Hydrobiologia 398/399: 211215.

Darquy S, Sun AM. 1987. Microencapsulation of parathyroid cells as a bioartificial parathyroid in vitro studies. ASAIO J. 33: 356358.

Fan MY, Lum ZP, Fu XW, Levesque L, Tai IT, Sun AM. 1990. Reversal of diabetes in BB rats in transplantation of encapsulation pancreatic islets. Diabetes 39: 519-522.

Fonteles MC, Cohen JJ, Black AJ, Wertheim SJ. 1983. Support of renal kidney function by long-chain fatty acids derived from renal tissue. Am. J. Physiol. 244: 235-246.

Fujiihara M, Izimma N, Yamamoto I, Nagumo T. 1984. Purification and chemical and physical characterization of an antitumor polysaccharide from the brown seaweed Sargassum fulvellum. Carbohydr. Res. 125: 97-106.

Fujihara M, Nagumo T. 1992. The effect of the content of D-mannuronic acid and L-guluronic acid blocks in alginates on antitumor activity. Carbohydr. Res. 224: 343-347.

Fujihara M, Nagumo T. 1993. An influence of the structure of alginate on the chemotactic activity of macrophage and the antitumor activity. Carbohydr. Res. 243: 211-216.

Hagen A, Skjak-Braek G, Dornish M. 1996. Pharmacokinetics of sodium alginate in mice. Eur. J. Pharm. Sci. 4(suppl 1): S100.

Ireland CM, Copp BR, Foster MP, McDonald LA, Radisky DC, Swersey C. 1993. Biomedical potential of marine natural products. In Marine Biotechnology: Pharmaceutical and Bioactive Natural Products, Attaway DH, Zaborsky OR (eds). Plenum Publishing Corporation: New York; 1-37.

Lai HL, Abu'Khalil A, Craig DQ. 2003. The preparation and characterization of drug-loaded alginate and chitosan sponges. Int. J. Pharm. 251: 175-181.

Leung MYK, Liu C, Koon JCM, Fung KP. 2006. Polysaccharide biological response modifiers. Immunol. Lett. 105: 101-114.

Martinez-Maldonado M, Opava-Stitzer S. 1978. Free water clearance curves during saline, mannitol, glucose and urea. J. Physiol. 280: 487-497.

McGregor DD. 1965. The effect of sympathetic nerve stimulation on vasoconstrictor responses in perfused mesenteric blood vessels of the rat. J. Physiol. 177: 21-30.

Mitsuhashi H, Suemaru K, Li B, Cui R, Araki H. 2006. Evaluation of topical external medicine for 5-fluorouracil-induced oral mucositis in hamsters. Eur. J. Pharmacol. 551: 152-155.

Moe ST, Draget KI, Skjåk-Bræk G, Smidsrød O. 1995. Alginates. In Food Polysaccharides, Stephen AM (ed.). Marcel Dekker: New York; 245-286.

Ooi VEC, Liu F. 2000. Immunomodulation and anti-cancer activity of polysaccharide-protein complexes. Curr. Med. Chem. 7: 715-729.

Pandey R, Ahmad Z, Sharma S, Khuller GK. 2005. Nano-encapsulation of azole antifungals: potential applications to improve oral drug delivery. Int. J. Pharm. 301: 268-276.

Panikkar R, Brasch DJ. 1996. Composition and block structure of alginates from New Zealand brown seaweeds. Carbohydr. Res. 293: 119-132.

Smit AJ. 2004. Medicinal and pharmaceutical uses of seaweed natural products: A review. J. Appl. Phycol. 16: 245-262.

Sousa APA, Torres MR, Pessoa C, Moraes MO, Rocha Filho FD, Alves APNN, Costa-Lotufo LV. 2007. In vivo growth-inhibition of sarcoma 180 tumor by alginates from brown seaweed Sargassum vulgare. Carbohydr. Polymers 69: 7-13.

Torres MR. 2003. Purificação, Caracterização Físico-química, Atividades Inflamatória e Imunoadjuvante de Alginatos da Alga Marinha Sargassum vulgare C. Agardh. $\mathrm{PhD}$ thesis. Biochemistry Department, Federal University of Ceara.

Walser M, Davidson DG, Orloff J. 1955. The renal clearance of alkalistable inulin. J. Clin. Invest. 34: 1520-1523. 